\title{
A new RP-HPLC method for simultaneous quantification of perindopril erbumine, indapamide, and amlodipine besylate in bulk and pharmaceutical dosage form
}

\author{
Kirtan P. Patel, Usmangani K. Chhalotiya ${ }^{*}$, Hetaben M. Kachhiya and Jay K. Patel
}

\begin{abstract}
Background: Perindopril erbumine is a specific inhibitor of angiotensin-converting enzyme, indapamide is the one providing thiazide diuretic effect, and amlodipine besylate is a calcium antagonist which belongs to the dihydropyridines which helps to maintain the pressure of the blood in the patient having arterial hypertension. The literature survey discloses that only one method is available for the estimation of the combination in the quantitative analytical liquid chromatographic method. Moreover to this, the literature review also reveals that HPTLC, UV spectroscopy, and HPLC methods are available for the analysis of either of the two in combination. Hence, our area of interest is to develop and validate the RP-HPLC in order to quantify perindopril erbumine, indapamide, and amlodipine besylate simultaneously in bulk and formulation.
\end{abstract}

Result: Sensitive and accurate RP-HPLC method was developed for the simultaneous estimation of indapamide, perindopril erbumine, and amlodipine besylate in bulk and available as triplixam-marketed tablet dosage form which is a combination of these drugs. The Phenomenex C-18 column ( $250 \mathrm{~mm} \times 4.6 \mathrm{~mm}, 5 \mu \mathrm{m})$ was used as a stationary phase, and acetonitrile: methanol: water (30:20:50, v/v/v) was found to be optimized mobile phase which was further adjusted to $\mathrm{pH} 3.0$ by utilizing $1.0 \%$ orthophosphoric acid; the flow rate kept was $1 \mathrm{ml} / \mathrm{min}$ and experiments were performed using PDA detector. The common detection wavelength for all the three APIs was found to be $215.0 \mathrm{~nm}$. The method was validated as per ICH Q2 (R1). The linearity range for amlodipine besylate was found to be $0.500-9.500 \mu \mathrm{g} / \mathrm{ml}$; for perindopril erbumine was found to be $0.400-7.600 \mu \mathrm{g} / \mathrm{ml}$, and for indapamide was found to be $0.125-2.375 \mu \mathrm{g} / \mathrm{ml}$. The correlation coefficient was found to be more than 0.9975 for all three of them, whereas the mean percentage recovery was found to be $99.52-100.71 \%, 99.49-100.89 \%$, and 99.90-100.78\%, respectively.

Conclusion: The proposed RP-HPLC method is found to be accurate and robust enough to estimate the perindopril erbumine, indapamide, and amlodipine besylate simultaneously in bulk and available tablet dosage form of combination.

Keywords: Indapamide, Amlodipine besylate, Perindopril erbumine, RP-HPLC, Validation

\footnotetext{
* Correspondence: usmangani84@gmail.com

Department of Pharmaceutical Chemistry and Analysis, Indukaka Ipcowala College of Pharmacy, Beyond GIDC, P.B. No. 53, VitthalUdyognagar, Gujarat 388 121, India
} 


\section{Background}

Perindopril erbumine, indapamide, and amlodipine besylate are three APIs generally used to treat hypertension. (2S,3aS,7aS)-1-[(2S)-2-[[(2S)-1-ethoxy-1-oxopentan-2-

yl]amino]propanoyl]-2,3,3a,4,5,6,7,7a octahydroindole-2carboxylicacid;2-methylpropan-2-amine is the chemical name of perindopril erbumine (PER) which is active component of an angiotensin-converting enzyme inhibitor (ACE-I). Apart from this, the other diseased conditions which can be cured using this are heart attacks, strokes, and kidney problem [1].

The chemical name of indapamide (IND) is 4-chloro$N$-(2-methyl-2,3-dihydroindol-1-yl)-3-sulfamoylbenzamide. It belongs to the thiazide diuretics class and generally used for the treatment of salt and fluid retention associated with congestive heart failure or edema from pregnancy and also found to be the oral antihypertensive drug [2].

The chemical name of amlodipine besylate (AML) is 3O-ethyl 5-O-methyl 2-(2-aminoethoxymethyl)-4-(2-chlorophenyl)-6-methyl-1,4-dihydropyridine- 3,5dicarboxylate; benzenesulfonic acid which is a well-known antihypertensive drug which belongs to calcium channel blockers [3]. The structures of all three chemical moieties, i.e., APIs are shown in Fig. 1.

The main purpose of this composition of three drugs is to regulate blood pressure in the patient suffering from arterial hypertension. The intake of this as once in a day is generally administered for better treatment [1-3].

The literature survey showed that only one method for the estimation of these drugs in combination is available by the quantitative analytical liquid chromatographic method [4]. Apart from this, HPLC, HPTLC, and UV spectrophotometric techniques were only reported for the determination of these APIs either alone or in dual combinations [5-27]. Moreover, this one HPTLC method was also found to quantify and estimate PER, IND, and AML simultaneously in bulk as well as a pharmaceutical formulation which is a tablet dosage form [28].
The RP-HPLC method has a distinct advantage over the HPTLC method in terms of sensitivity, resolution, and economic and is compatible with a wide range of detectors [29].

The present work includes the developed and validated RP-HPLC method as per ICH Q2 (R1) for the simultaneous analysis of PER, IND, and AML in bulk as well as pharmaceutical dosage form [29].

\section{Methods \\ Materials}

PER, IND, and AML were procured from the reputed pharmaceutical industry, Gujarat, India. Solvents and reagent like methanol (HPLC grade)-SRL Chemicals Pvt. Ltd., Ahmedabad, India; ACN (AR grade)-Astron chemicals Pvt Ltd., Ahmedabad, India; and 1.0\% orthophosphoric acid (OPA) (AR grade)-Astron chemicals, Ahmedabad, India, were purchased. Triplixam tablet (Serdia Pharmaceutical Ltd.) was used having label claim: Each tablet contains perindopril erbumine $4 \mathrm{mg}$, indapamide 1.25, and amlodipine besylate $5 \mathrm{mg}$.

\section{Instrument}

Analytical balance making a model of Mettler Toledo electronic balance (ME204, Mettler Toledo Group, Mumbai, India) was used. HPLC System of Waters HPLC system consisted of a binary pump (model Waters 515 HPLC pump), loop injector, and PDA detector (Waters 2998) were connected with empower - version 2 software. Phenomenex C-18 column $(250 \mathrm{~mm} \times 4.6 \mathrm{~mm}, 5.0 \mu)$ was used as a stationary phase for the better separation compound.

\section{Chromatographic conditions}

The Phenomenex C-18 column $(250 \mathrm{~mm} \times 4.6 \mathrm{~mm}$, $5.0 \mu)$ equilibrated with mobile phase acetonitrile: methanol: water (30:20:50, v/v/v) was further adjusted to pH 3.0 with the help of $1.0 \%$ ortho-phosphoric acid. The flow rate was kept to be $1 \mathrm{ml} / \mathrm{min}$, eluents were supervised using a PDA detector at $215.0 \mathrm{~nm}$ with the fixed

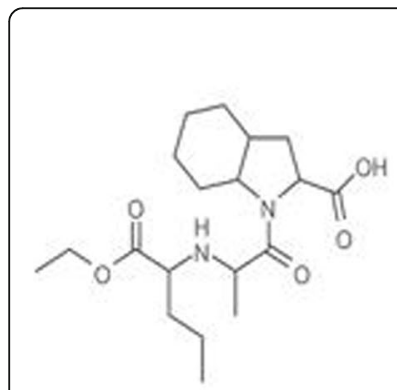

(A)

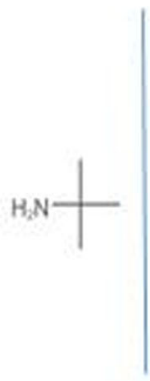

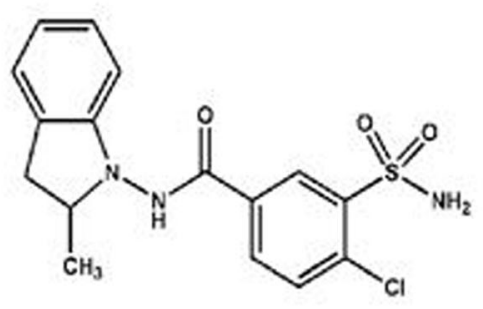

(B)<smiles></smiles>

(C)

Fig. 1 Chemical structure of (a) Perindopril erbumine, (b) Indapamide, and (c) Amlodipine besylate 
volume of injection that was $20 \mu \mathrm{l}$, and the stop time optimized was $11 \mathrm{~min}$.

\section{Preparation of standard stock solution}

Weight accurately PER (4.0 mg), IND (1.25 mg), and AML $(5.0 \mathrm{mg})$ and transferred to three different $10 \mathrm{ml}$ volumetric flasks containing a minute amount of methanol $(5.0 \mathrm{ml})$. Volumes were to be adjusted up to the mark with methanol to yield the strength of solution containing $400 \mu \mathrm{g} / \mathrm{ml}$ of PER, $125 \mu \mathrm{g} / \mathrm{ml}$ of IND, and $500 \mu \mathrm{g} / \mathrm{ml}$ of AML. Pipette out $1.0 \mathrm{ml}$ from each of the above solutions and mix into $10 \mathrm{ml}$ volumetric flask, make up to the mark with the mobile phase. The working standard solutions of $40 \mu \mathrm{g} / \mathrm{ml}$ of PER, $12.5 \mu \mathrm{g} / \mathrm{ml}$ of IND, and $50 \mu \mathrm{g} / \mathrm{ml}$ of AML were prepared.

\section{Validation of the developed RP-HPLC method}

Validation of the proposed developed RP-HPLC method was performed according to ICH Q2 (R1) for the accuracy, precision, robustness, and various other typical parameters.

\section{Linearity and range}

Appropriate aliquots of PER, IND, and AML working standard solution of 7 different concentration was taken in different $10-\mathrm{ml}$ volumetric flasks and diluted up to the mark with a mobile phase to obtain a final concentration of $0.40,1.60,2.80,4.00,5.20,6.40$, and $7.60 \mu \mathrm{g} /$ $\mathrm{ml}$ of PER; $0.125,0.500,0.875,1.25,1.625,2.0$, and $2.375 \mu \mathrm{g} / \mathrm{ml}$ of IND; and 0.50, 2.00, 3.50, 5.00, 6.50, 8.00, and $9.50 \mu \mathrm{g} / \mathrm{ml}$ of AML. The solution was injected using a $20-\mu$ l fixed loop system and the chromatogram was recorded. The calibration curve constructed by plotting the average peak area against concentrations and regression equation was computed $(n=5)$.

\section{Precision}

Intraday and interday as intermediate precision were performed as a part of precision. Working standard solutions of $40 \mu \mathrm{g} / \mathrm{ml}$ of PER, $12.5 \mu \mathrm{g} / \mathrm{ml}$ of IND, and $50 \mu \mathrm{g} /$ $\mathrm{ml}$ of AML were prepared and analyzed as a part of the precision study. Intraday precision was performed for the solutions of PER, IND, and AML mixture at 3 levels covering respectively of lower $(0.400,0.125,0.500 \mu \mathrm{g} /$ $\mathrm{ml})$, medium $(4.0,1.25,5.0 \mu \mathrm{g} / \mathrm{ml})$, and higher $(7.60$, $2.75,9.50 \mu \mathrm{g} / \mathrm{ml}$ ) concentration of the calibration curve analyzed three times on the same day. Interday precision was determined by analyzing the sample solution of PER, IND, and AML mixture at three levels covering lower, medium, and higher concentration periods for three different days. Mean and \%RSD values were calculated by using the obtained peak area.

The repeatability was studied by injecting six times of the middle concentration of the calibration range and estimating the area of each injection and determines the \%RSD.

\section{Accuracy}

The accuracy of the method was determined by calculating the recovery of PER, IND, and AML by the method of standard addition. The known amount of PER, IND, and AML at three levels of 80, 100, and 120\% were spiked to prequantified sample solution, and the amount of $2.24,2.80$, and $3.36 \mu \mathrm{g} / \mathrm{ml}$ of PER; $0.70,0.88$, and $1.05 \mu \mathrm{g} / \mathrm{ml}$ of IND; and 2.80, 3.50, and $4.20 \mu \mathrm{g} / \mathrm{ml}$ of AML was added to prequantified sample solution. By putting the values of area to the calibration curve, the percentage (\%) recoveries of PER, IND, and AML were estimated and regression analysis was carried out.

\section{Detection limit and quantitation limit}

The lowest concentration of drug which can be reliably detected and differentiate from the background is known as a limit of detection (LOD) and which can be quantified at the lowest concentration is known as LOQ, i.e., the limit of quantification. LOD and LOQ were calculated using the following equation as per $\mathrm{ICH}$ guidelines.

$$
\mathrm{LOD}=3.3 \times \sigma / \mathrm{SD}
$$$$
\mathrm{LOQ}=10 \times \sigma / \mathrm{SD}
$$

where $\sigma$ is the standard deviation of $y$-intercept of the regression line and $S$ is the slope of the calibration curve.

\section{Specificity}

The specificity studies have been carried out by spiking commonly used excipients into a preweighed quantity of active pharmaceutical ingredients. The chromatogram was recorded for the appropriate dilution.

\section{Robustness}

Robustness of the method was studied by providing deliberate changes in the experimenting condition like mobile phase, temperature, and wavelength and flow rate. The mean and \%RSD of peak retention time was calculated.

\section{Solution stability}

The stock standard solutions of the mixture were stored at normal room temperature for $48 \mathrm{~h}$ and were estimated using RP-HPLC at a specific time interval of $0,8,24,36$, and $48 \mathrm{~h}$. The standard stock solution of $40 \mu \mathrm{g} / \mathrm{ml}$ of PER, $12.5 \mu \mathrm{g} / \mathrm{ml}$ of IND, and $50 \mu \mathrm{g} / \mathrm{ml}$ of AML was prepared. From the above, the stock solution withdrawn was $1.0 \mathrm{ml}$ and was transferred into another $10.0 \mathrm{ml}$ volumetric flask and make up the volume up to the mark with a mobile phase to obtain the final concentration $4.0 \mu \mathrm{g} / \mathrm{ml}$ for PER, $1.25 \mu \mathrm{g} / \mathrm{ml}$ for IND, and $5.0 \mu \mathrm{g} / \mathrm{ml}$ for $A M L$ and used for the 


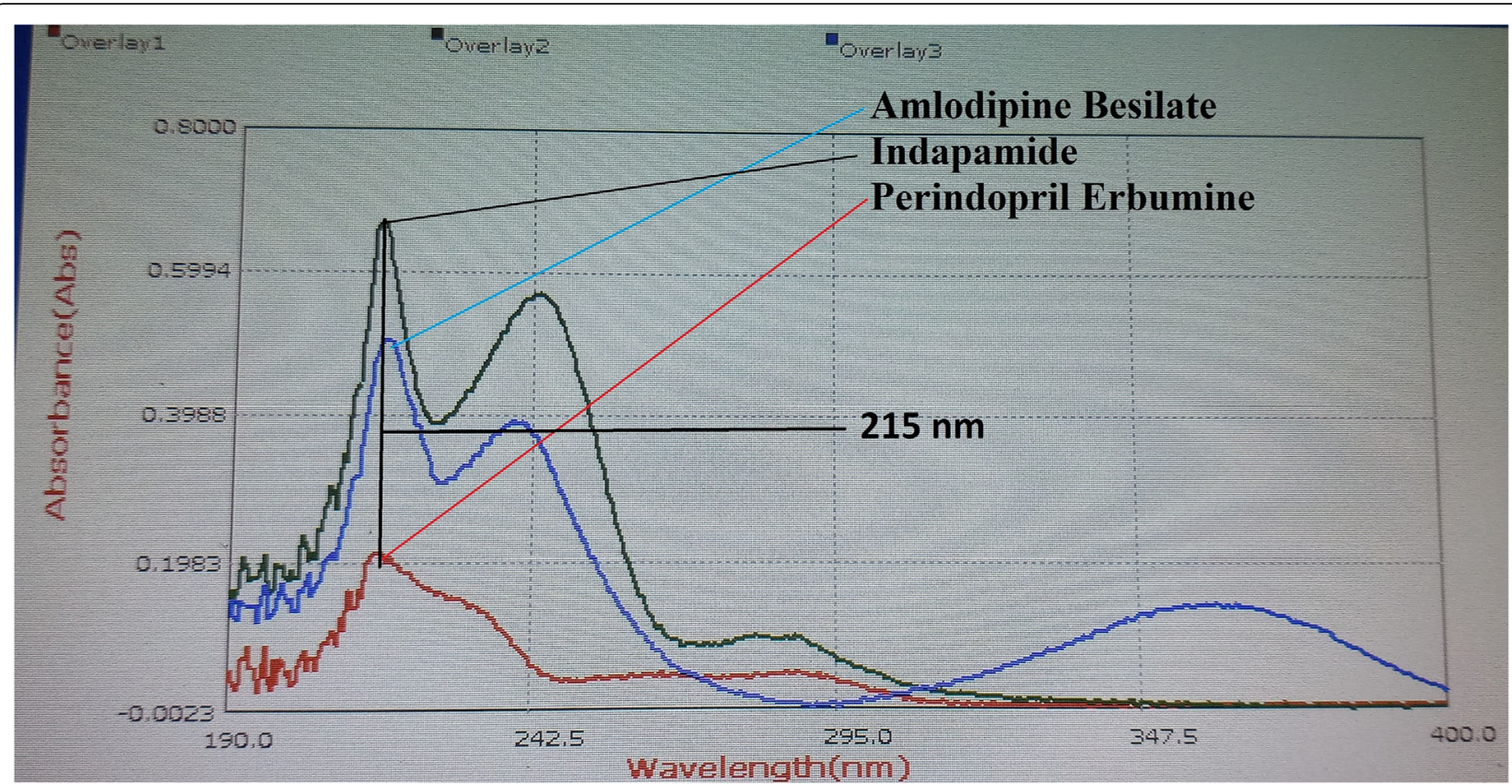

Fig. 2 UV visible overlay spectra of Perindopril erbumine, Indapamide, and Amlodipine besylate for selection of analytical wavelength (10 $\mu \mathrm{g} / \mathrm{ml})$

solution stability studies. The solution stability study of the solution was studied by applying and analyzing it three times in the middle concentration of the calibration range.

\section{System suitability}

A system suitability test was an integral part of the process development to verify that the system is appropriate for the analysis of PER, IND, and AML to be carried out. The system suitability test for the proposed chromatographic system was performed following the validation run. Six replicate injections of a standard and one injection of a sample were made and evaluated the efficiency of the system by verification of different parameters like $R_{\mathrm{t}}$, resolution, asymmetric factor, and theoretical plate.

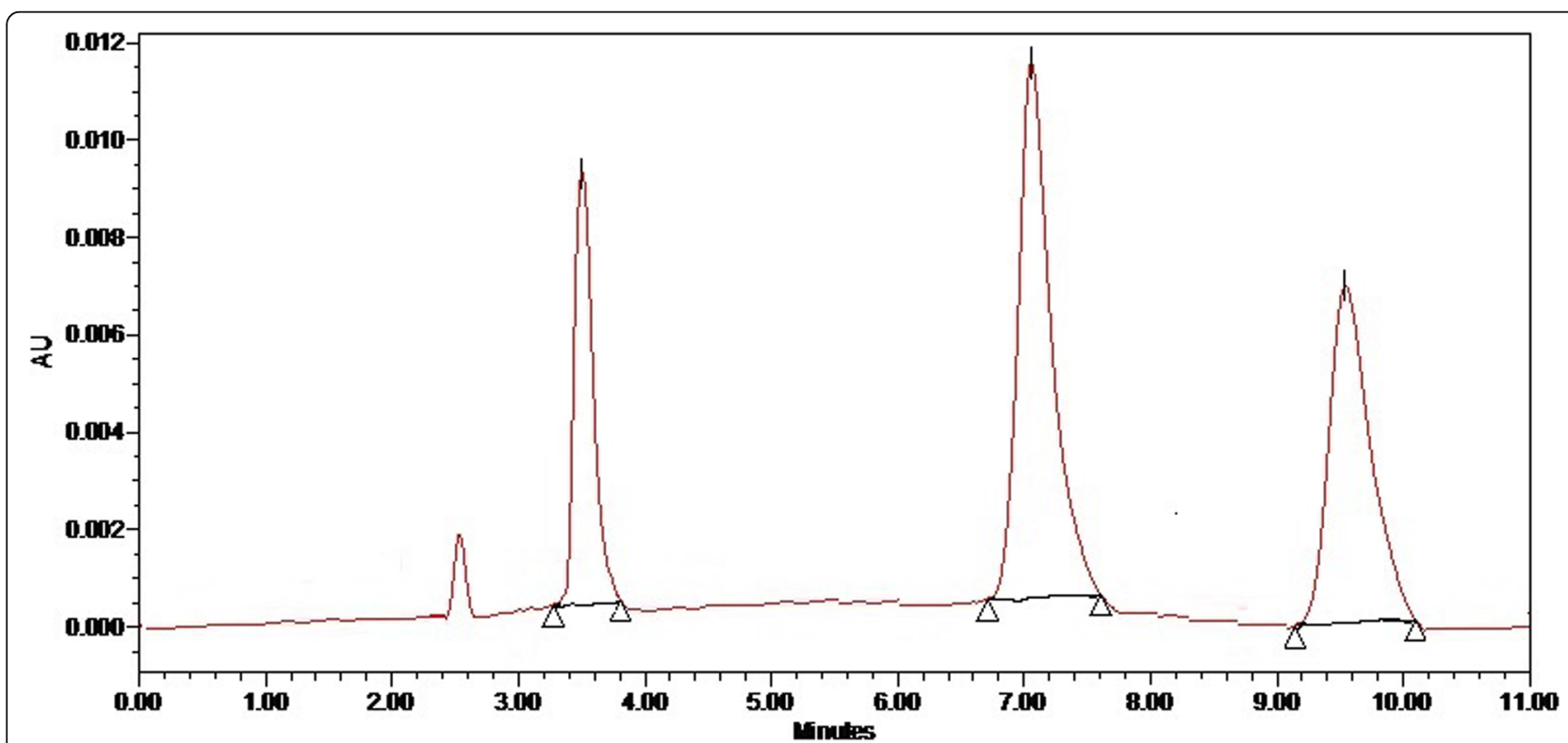

Fig. 3 Chromatogram for Perindopril erbumine $(4 \mu \mathrm{g} / \mathrm{mL})$, Indapamide $(1.25 \mu \mathrm{g} / \mathrm{mL})$, and Amlodipine besylate $(5 \mu \mathrm{g} / \mathrm{mL})$ using mixture of acetonitrile: methanol: water (30:20:50, v/v/v) was further adjusted to $\mathrm{pH} 3.0$ with 1.0\% O-phosphoric acid as a mobile phase 


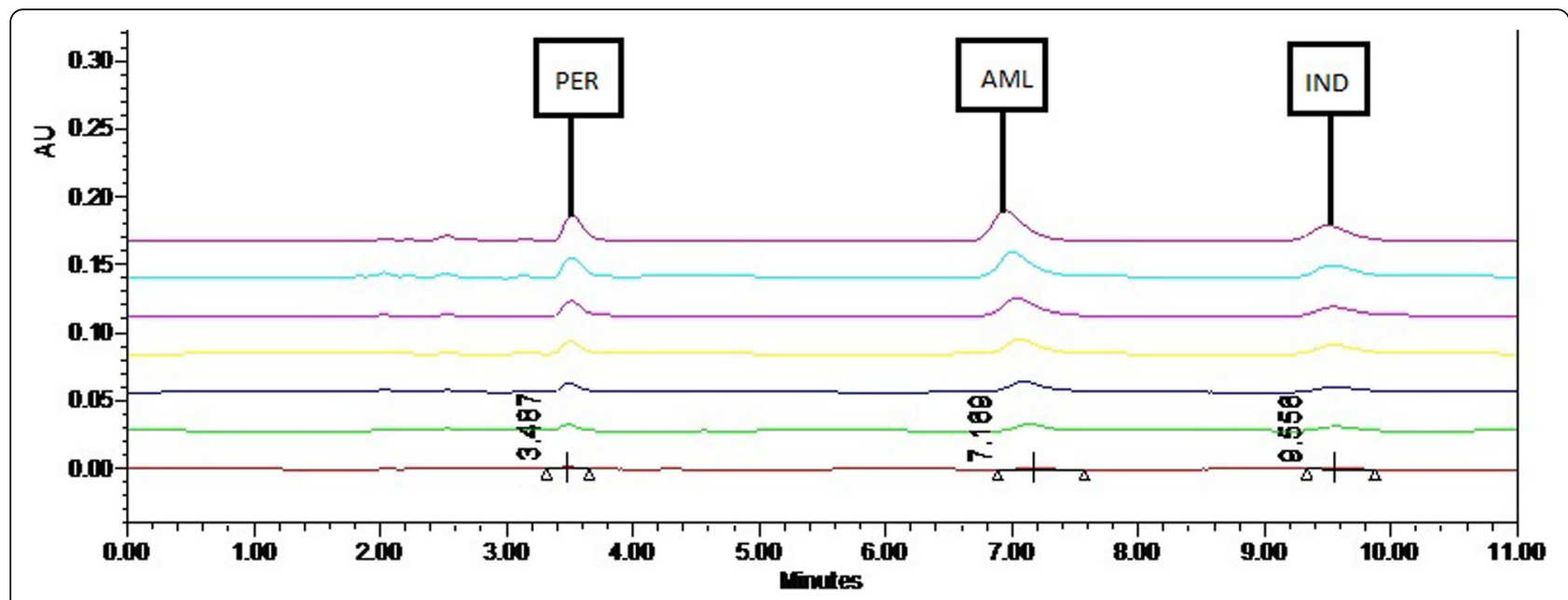

Fig. 4 Overlay chromatogram of Perindopril erbumine $(0.4-7.6 \mu \mathrm{g} / \mathrm{ml})$, Indapamide $(0.125-2.375 \mu \mathrm{g} / \mathrm{ml})$, and Amlodipine besylate $(0.5-9.5 \mu \mathrm{g} / \mathrm{ml})$

\section{Analysis of marketed formulations}

Finely powdered and accurately weighted twenty tablets were prepared by using a mortar pestle. The powder equivalent to $4.0 \mathrm{mg}$ of PER, $1.25 \mathrm{mg}$ of IND, and $5.0 \mathrm{mg}$ of AML was accurately weighed and transferred to a 10$\mathrm{ml}$ volumetric flask containing minute $\mathrm{ml}(5.0 \mathrm{ml})$ of methanol and flask was sonicated for $5.0 \mathrm{~min}$. The solution was filtered into using the Whatman filter paper (No. 42), the residues were washed twice with a few $\mathrm{ml}$ of methanol, and both filtrate and washing were combined in the same volumetric flask. The volume was adjusted to the mark with the methanol. From the above solution, pipetted out $1.0 \mathrm{ml}$ of aliquots was transferred into another $10 \mathrm{ml}$ volumetric flask and the volume was made up to the mark with methanol to obtain the concentration of stock solutions $40 \mu \mathrm{g} / \mathrm{ml}$ of PER, $12.5 \mu \mathrm{g} /$ $\mathrm{ml}$ of IND, and $50 \mu \mathrm{g} / \mathrm{ml}$ AML. $1.0 \mathrm{ml}$ above stock solution was pipetted out into another $10 \mathrm{ml}$ volumetric flask and make up the volume up to the mark with a mobile phase to obtain a final concentration $4.0 \mu \mathrm{g} / \mathrm{ml}$ of PER,
$1.25 \mu \mathrm{g} / \mathrm{ml}$ of IND, and $5.0 \mu \mathrm{g} / \mathrm{ml}$ of AML, respectively. $100 \mu \mathrm{l}$ Hamilton syringe was used to inject the middle concentration of the calibration range of these solutions, and all the three drugs were simultaneously estimated by the proposed chromatographic method. The percentage (\%) amount of PER, IND, and AML was noted by using the regression equation.

\section{Result}

Mobile phase optimization

The objective of the method development was to obtain well-resolved chromatographic peaks of APIs; PER, IND, and AML. Various compositions and different proportions of solvents comprising buffer, methanol, water, and $\mathrm{ACN}$ were tried as a mobile phase. The mobile phases like methanol to water $(70: 30, \mathrm{v} / \mathrm{v})$ was used but it has a poor resolution of peaks observed of active drugs; acetonitrile to water $(70: 30, \mathrm{v} / \mathrm{v})$ was tried where PER peak merged with void volume peak and AML showed tailing;

Table 1 Statistical data of calibration curve

\begin{tabular}{lllr}
\hline Parameters & Perindopril erbumine & Indapamide & Amlodipine besylate \\
\hline Concentration range $(\mu \mathrm{g} / \mathrm{ml})$ & $0.400-7.60$ & $0.125-2.375$ & $0.500-9.50$ \\
Regression coefficient $\left(r^{2}\right)$ & 0.9979 & 0.9980 & 0.9980 \\
Slope of regression & 22178.4 & 85598.4 & 36123.2 \\
Standard deviation of slope & 152.16 & 558.97 & 70.38 \\
Intercept of regression & 8196.9 & 2130.0 & 7844.5 \\
Standard deviation of Intercept & 438.18 & 482.85 & 606.84 \\
Detection limit $(\mu \mathrm{g} / \mathrm{ml})$ & 0.065 & 0.019 & 0.055 \\
Quantitation limit $(\mu \mathrm{g} / \mathrm{ml})$ & 0.198 & 0.056 & 0.168 \\
\hline
\end{tabular}


Table 2. Result of proposed accuracy study

\begin{tabular}{|c|c|c|c|c|c|c|c|c|c|}
\hline \multirow{2}{*}{$\begin{array}{l}\text { Level } \\
\% \\
\text { Spiked } \\
\end{array}$} & \multicolumn{3}{|c|}{$\begin{array}{l}\text { Initial conc. } \\
(\mu \mathrm{g} / \mathrm{ml})\end{array}$} & \multicolumn{2}{|c|}{ Perindopril erbumine } & \multicolumn{2}{|l|}{ Indapamide } & \multicolumn{2}{|c|}{ Amlodipine besylate } \\
\hline & PER & IND & AML & $\begin{array}{l}\text { Area } \pm \text { SD }(n= \\
3)\end{array}$ & $\begin{array}{l}\text { \%Recovery } \pm \text { SD } \\
(n=3)\end{array}$ & $\begin{array}{l}\text { Area } \pm \text { SD }(n= \\
3)\end{array}$ & $\begin{array}{l}\text { \%Recovery } \pm \text { SD } \\
(n=3)\end{array}$ & Area \pm SD $(n=3)$ & $\begin{array}{l}\text { \%Recovery } \pm \text { SD } \\
(n=3)\end{array}$ \\
\hline $0 \%$ & 2.8 & 0.88 & 3.5 & $\begin{array}{l}70004.0 \pm \\
118.57\end{array}$ & $99.53 \pm 0.19$ & $\begin{array}{l}77693.0 \pm \\
617.07\end{array}$ & $100.89 \pm 0.83$ & $\begin{array}{l}135263.3 \pm \\
579.01\end{array}$ & $100.78 \pm 0.46$ \\
\hline $80 \%$ & 2.8 & 0.88 & 3.5 & $\begin{array}{l}120086.3 \pm \\
890.59\end{array}$ & $100.17 \pm 1.43$ & $\begin{array}{l}136565.7 \pm \\
518.23\end{array}$ & $99.49 \pm 0.69$ & $\begin{array}{l}23.5430 .3 \pm \\
1146.05\end{array}$ & $100.01 \pm 0.90$ \\
\hline $100 \%$ & 2.8 & 0.88 & 3.5 & $\begin{array}{l}132643.3 \pm \\
565.76\end{array}$ & $100.39 \pm 0.91$ & $\begin{array}{l}151712.0 \pm \\
410.20\end{array}$ & $99.71 \pm 0.55$ & $260573.0 \pm 668.8$ & $99.90 \pm 0.53$ \\
\hline $120 \%$ & 2.8 & 0.88 & 3.5 & $\begin{array}{l}145265.0 \pm \\
373.10\end{array}$ & $100.71 \pm 0.60$ & $\begin{array}{l}166581.0 \pm \\
906.93\end{array}$ & $99.57 \pm 1.21$ & $286747.7 \pm 956.7$ & $100.60 \pm 0.76$ \\
\hline
\end{tabular}

acetonitrile to water $(35: 65, \mathrm{v} / \mathrm{v}) \mathrm{pH} 4.0$ adjusted using $1.0 \%$ ortho-phosphoric acid was tried in which PER and AML were eluted at similar retention time; by using a mobile phase acetonitrile to methanol to water $(45: 20$ : $35, \mathrm{v} / \mathrm{v} / \mathrm{v})$, AML and PER have a good symmetric peak but the resolution is very poor because both drugs are eluted on the same retention time; by using mobile phase composition acetonitrile to methanol to water (20: 20:60, v/v/v) pH 3.0 adjusted with 1.0\% OPA, peak splitting and reduction in peak height are observed for PER and peak broadening is observed for IND. The well resolved, sharp, and symmetrical peaks peak for PER, IND, and AML $(10 \mu \mathrm{g} / \mathrm{ml})$ are observed with mobile phase acetonitrile to methanol to water $(30: 20: 50, \mathrm{v} / \mathrm{v} / \mathrm{v})$ at $\mathrm{pH}$ 3.0 adjusted with $1.0 \%$ ortho-phosphoric acid where the working standard solution was diluted with a mobile phase. The flow rate was maintained at $1.0 \mathrm{ml} / \mathrm{min}$. All three active pharmaceutical ingredients show an appreciable absorbance at a common wavelength $215.0 \mathrm{~nm}$ $\lambda_{\max }$ (Fig. 2). The elution time of PER, AML, and IND with optimum retention time was found to be $3.5 \pm 0.2$, $7.1 \pm 0.2$, and $9.6 \pm 0.3 \mathrm{~min}$ at a common wavelength $\lambda_{\max } 215.0 \mathrm{~nm}$, respectively (Fig. 3).

\section{Method validation Linearity and range}

A linear response was found to be within the concentration range of $0.400-7.60 \mu \mathrm{g} / \mathrm{ml}$ for PER, $0.125-2.375 \mu \mathrm{g} /$ $\mathrm{ml}$ for IND, and $0.500-9.50 \mu \mathrm{g} / \mathrm{ml}$ for AML $(n=5)$ along with respected peak area. Figure 4 represents an overlay chromatogram of PER, IND, and AML at 215.0 $\mathrm{nm}$ and shows a common absorbance wavelength by the proposed RP-HPLC method. Table 1 is representing the data of the regression analysis of the calibration curve.

\section{Precision}

The intraday and interday precision study has been carried out. The percentage (\%) RSD values were less than

Table 3. Robustness study of proposed method

\begin{tabular}{|c|c|c|c|c|c|c|c|c|}
\hline \multirow[t]{2}{*}{ Parameters } & \multirow[t]{2}{*}{ Normal condition } & \multirow{2}{*}{$\begin{array}{l}\text { Change } \\
\text { in } \\
\text { condition }\end{array}$} & \multicolumn{3}{|c|}{ Mean area \pm SD $(n=3)$} & \multicolumn{3}{|l|}{$\%$ RSD } \\
\hline & & & $\begin{array}{l}\text { PER }(4 \mu g / \\
\mathrm{mL})\end{array}$ & $\begin{array}{l}\text { IND } \\
(1.25 \mu \mathrm{g} / \\
\mathrm{mL})\end{array}$ & $\begin{array}{l}\text { AML } \\
(5 \mu \mathrm{g} / \mathrm{mL})\end{array}$ & $\begin{array}{l}\text { PER } \\
(4 \mu \mathrm{g} / \\
\mathrm{ml})\end{array}$ & $\begin{array}{l}\text { IND } \\
(1.25 \mu \mathrm{g} / \\
\mathrm{ml})\end{array}$ & $\begin{array}{l}\text { AML } \\
(5 \mu \mathrm{g} / \mathrm{ml})\end{array}$ \\
\hline \multirow[t]{2}{*}{$\begin{array}{l}\text { Change in mobile } \\
\text { phase ratio }\end{array}$} & $\begin{array}{l}\text { Acetonitrile :Methanol :Water } \\
(30: 20: 50, v / v / v) p H 3.0 \text { adjust with 1\% OPA }\end{array}$ & $\begin{array}{l}35: 20: 45 \\
\text { v/v/V }\end{array}$ & $\begin{array}{l}96342.33 \pm \\
1553.51\end{array}$ & $\begin{array}{l}108733 \pm \\
1697.85\end{array}$ & $\begin{array}{l}184767 \pm \\
3241.86\end{array}$ & 1.61 & 1.56 & 1.75 \\
\hline & & $\begin{array}{l}30: 25: 45 \\
\text { v/v/v }\end{array}$ & $\begin{array}{l}95567.00 \pm \\
1185.70\end{array}$ & $\begin{array}{l}108541 \pm \\
1894.39\end{array}$ & $\begin{array}{l}186363 \pm \\
2687.21\end{array}$ & 1.24 & 1.75 & 1.44 \\
\hline \multirow[t]{2}{*}{$\begin{array}{l}\text { Change in } \\
\text { wavelength }\end{array}$} & $215 \mathrm{~nm}$ & $214 \mathrm{~nm}$ & $\begin{array}{l}95599.00 \pm \\
1436.38\end{array}$ & $\begin{array}{l}108503 \pm \\
1388.35\end{array}$ & $\begin{array}{l}185474 \pm \\
3323.43\end{array}$ & 1.50 & 1.28 & 1.79 \\
\hline & & $216 \mathrm{~nm}$ & $\begin{array}{l}95124.33 \pm \\
1666.298\end{array}$ & $\begin{array}{l}108227 \pm \\
1511.45\end{array}$ & $\begin{array}{l}186912 \pm \\
30511.9\end{array}$ & 1.75 & 1.40 & 1.63 \\
\hline \multirow[t]{2}{*}{$\begin{array}{l}\text { Change in } \\
\text { temperature }\end{array}$} & $25^{\circ} \mathrm{C}$ & $30^{\circ} \mathrm{C}$ & $\begin{array}{l}96040.67 \pm \\
1481.23\end{array}$ & $\begin{array}{l}108799 \pm \\
1573.84\end{array}$ & $\begin{array}{l}185215 \pm \\
3063.14\end{array}$ & 1.54 & 1.45 & 1.65 \\
\hline & & $20^{\circ} \mathrm{C}$ & $\begin{array}{l}96643.00 \pm \\
1463.39\end{array}$ & $\begin{array}{l}107725 \pm \\
1778.23\end{array}$ & $\begin{array}{l}186250 \pm \\
3507.47\end{array}$ & 1.51 & 1.65 & 1.88 \\
\hline \multirow[t]{2}{*}{$\begin{array}{l}\text { Change in flow } \\
\text { rate }\end{array}$} & $1.0 \mathrm{ml} / \mathrm{min}$ & $\begin{array}{l}0.9 \mathrm{ml} / \\
\min \end{array}$ & $\begin{array}{l}96182.67 \pm \\
1385.97\end{array}$ & $\begin{array}{l}108906 \pm \\
1343.03\end{array}$ & $\begin{array}{l}187229 \pm \\
2509.65\end{array}$ & 1.44 & 1.23 & 1.34 \\
\hline & & $\begin{array}{l}1.1 \mathrm{ml} / \\
\min \end{array}$ & $\begin{array}{l}96400.67 \pm \\
1736.06\end{array}$ & $\begin{array}{l}10258 \pm \\
1499.96\end{array}$ & $\begin{array}{l}187316 \pm \\
2661.07\end{array}$ & 1.80 & 1.39 & 1.42 \\
\hline
\end{tabular}


Table 4. Summary of validation parameter by proposed method

\begin{tabular}{llll}
\hline Parameters & Perindopril erbumine & Indapamide & Amlodipine besylate \\
\hline $\begin{array}{l}\text { Retention time } \\
\text { Precision } \\
\quad \text { Repeatability (\%RSD) } \\
\quad \text { Injection (n=6) } \\
\text { Intermediate (\%RSD) }\end{array}$ & $9.5 \pm 0.2$ & & $7.1 \pm 0.2$ \\
$\quad$ Intraday (n=3) & 1.04 & 0.3 & 0.48 \\
$\quad$ Interday (n=3) & $0.51-0.77$ & & \\
Accuracy (\% Recovery) & $0.90-1.58$ & $0.62-1.00$ & $0.77-0.93$ \\
Robustness & $99.52-100.71$ & $1.05-1.34$ & $1.18-1.44$ \\
Specificity & Robust & $99.49-100.89$ & $99.90-100.78$ \\
\hline
\end{tabular}

$2 \%$, confirming the precision of the method. Injection repeatability precision studied was perform by injecting and analyzing the sample with a concentration of $4.0 \mu \mathrm{g} /$ $\mathrm{ml}$ for PER, $1.25 \mu \mathrm{g} / \mathrm{ml}$ for IND, and $5.0 \mu \mathrm{g} / \mathrm{ml}$ for AML six times, and the percentage (\%) RSD was found to be less than $2.0 \%$, which was confirmed the instrumental specifications.

\section{Accuracy}

The accuracy study of the proposed method was determined by calculating recoveries of PER, IND, and AML, where a known amount of standard was spiked into a pre-analyzed sample solution. Table 2 is representing the data of the accuracy study, and the percentage (\%) recovery values were found to be more than $98 \%$.

\section{Limit of detection and limit of quantification}

By using the proposed experimental conditions, the lowest detectable amount of drug (LOD) was found to be $0.065,0.019$, and 0.055 , and also, the lowest quantifiable amount of drug (LOQ) was found to be 0.198, 0.056, and 0.168 for PER, IND, and AML, respectively.

\section{Specificity}

There was no interference of other elements present in the commercial formulation which is confirming the specificity of the proposed method.

\section{Robustness}

The robustness studies were performed by introducing little deliberate changes in proposed chromatographic

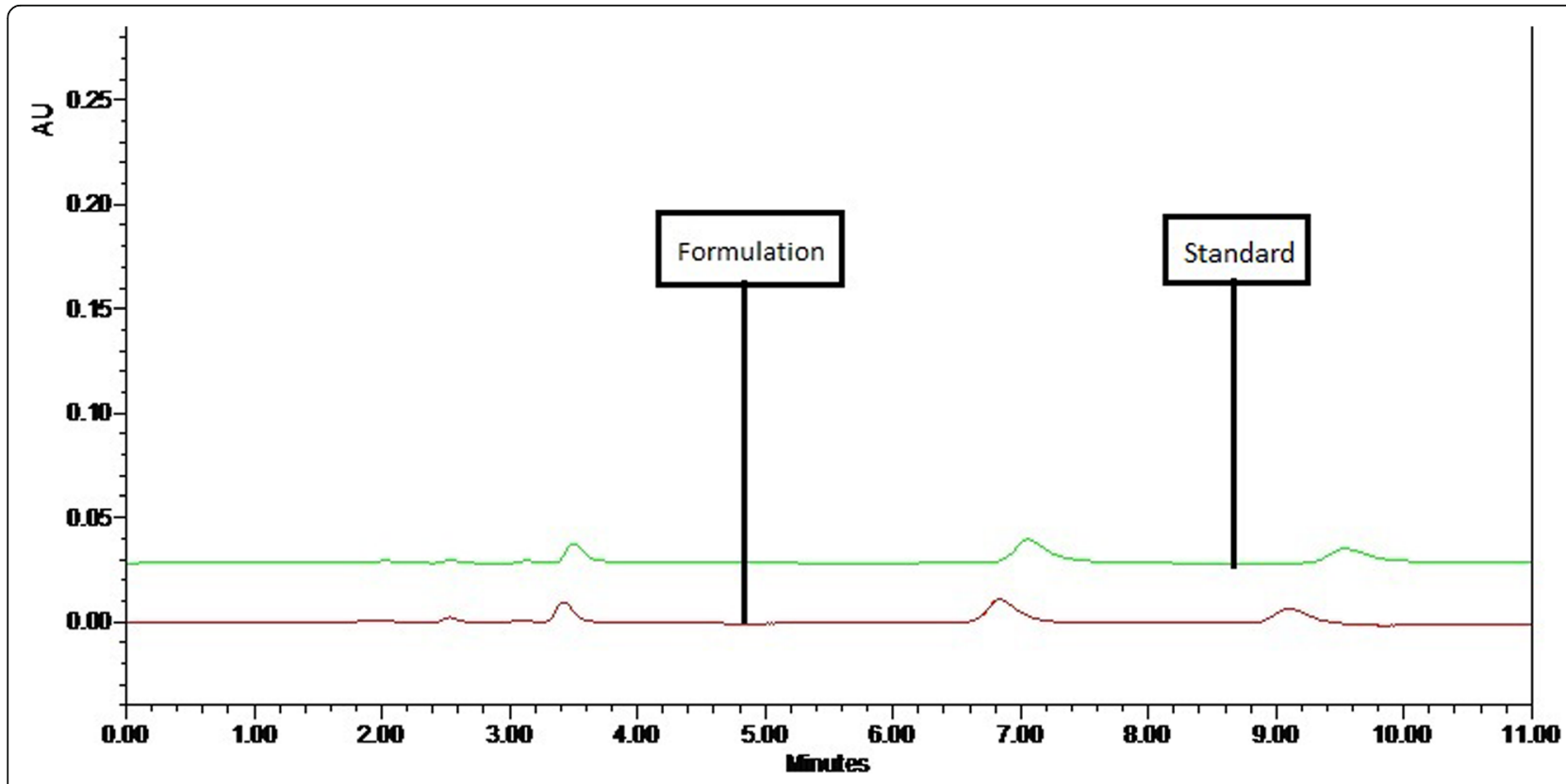

Fig. 5 Overlay chromatogram comparison of active pharmaceutical ingredient and marketed formulation 
Table 5. Assay result of marketed formulation

\begin{tabular}{llcll}
\hline Formulation & Name drug & $\begin{array}{l}\text { Conc. } \\
(\boldsymbol{\mu} \mathbf{g} / \mathbf{m l})\end{array}$ & Amount found \pm SD $(\boldsymbol{n}=\mathbf{3})$ & \% Amount of drug found \pm SD $(\boldsymbol{n}=\mathbf{3})$ \\
\hline Triplixam & Perindopril erbumine & 4.0 & $3.96 \pm 0.03$ & $99.03 \pm 0.80$ \\
& Indapamide & 1.25 & $1.26 \pm 0.01$ & $100.64 \pm 0.74$ \\
& Amlodipine besylate & 5.0 & $4.97 \pm 0.04$ & $99.35 \pm 0.78$ \\
\hline
\end{tabular}

Each tablet contain: Perindopril erbumine $-4.0 \mathrm{mg}$, Indapamide $-1.25 \mathrm{mg}$ and Amlodipine besylate $-5.0 \mathrm{mg}$

condition parameters like change in detection wavelength, change in temperature, change in mobile phase ratio, and change in flow rate. The retention time and percentage (\%) RSD value were measured for each condition. The percentage (\%) RSD value was found to be less than $2.0 \%$, which indicates that the method is robust. The results of the robustness of the proposed RP-HPLC method are shown in Table 3.

\section{Solution stability}

The solution stability study expressed that PER, IND, and AML solutions were found to be stable for $48 \mathrm{~h}$ at ambient temperature and humidity. The percentage amount of the drugs was calculated which was greater than $98 \%$.

\section{System suitability}

The system suitability study was performing for evaluation parameters like the resolution, theoretical plate, capacity factor, and asymmetric factor.

Table 4 is representing the summary of validation parameters by the proposed RP-LC method.

\section{Analysis of marketed formulation}

The proposed method is applied for the quantification of PER, IND, and AML in their pharmaceutical dosage form. The percentage (\%) amounts of drugs were found to be more than $98 \%$. Figure 5 was represented by the overlay chromatogram of the standard and marketed formulation, and the data of the assay of marketed formulation were shown in Table 5.

\section{Discussion (https://www.pharmatutor.org/articles/ high-performance-thin-layer-chromatography- hptlc-instrumentation-overview)}

The proposed studies include the development of the RP-HPLC method for estimation of PER, IND, and AML simultaneously in bulk and marketed formulation. The RP-HPLC method was developed, and the separation was carried out on stationary phase Phenomenex $\mathrm{C}_{18}$ column $(250 \mathrm{~mm} \times 4.6 \mathrm{~mm}, 5 \mu \mathrm{m})$ through isocratic elution using acetonitrile to methanol to water $(30: 20: 50, \mathrm{v} / \mathrm{v} / \mathrm{v}) \mathrm{pH} 3.0$ adjusted with $1.0 \%$ ortho-phosphoric acid as a mobile phase at a flow rate of $1 \mathrm{ml} / \mathrm{min}$, and all three drugs are monitored on $215.0 \mathrm{~nm}$. The linearity for PER, IND, and AML was found to be $0.400-7.60 \mu \mathrm{g} / \mathrm{ml}, 0.125$ $2.375 \mu \mathrm{g} / \mathrm{ml}$, and $0.500-9.50 \mu \mathrm{g} / \mathrm{ml}$, respectively. Table 2 is representing the accuracy data, and the percentage of the recoveries for PER, IND, and AML were found to be $99.53-100.71 \%, 99.49-100.89 \%$, and $99.90-100.78 \%$, respectively. The specificity was carried out to check the interference of excipients used in the synthetic mixture, and the developed method was found to be specific. Table 3 represented the data of the robustness of the proposed developed analytical method which is used to measure its ability to remain unaffected by a small, but a deliberate change of the proposed method chromatographic conditions. It was estimated by small changes in the chromatographic conditions like change in detection wavelength $( \pm 1$ $\mathrm{nm})$, change in flow rate $( \pm 0.1 \mathrm{ml})$, mobile phase ratio, and temperature of working $\left( \pm 5^{\circ} \mathrm{C}\right)$ provided with deliberate changes. The described minor changes did not affect the symmetry of peak and retention time $\left(R_{\mathrm{t}}\right)$ of PER, IND, and AML which confirm the reliability of the method. The percentage amounts of drugs were found more than $98 \%$ for the assay of a synthetic mixture which specifies that the method provides accurate and precise results.

\section{Conclusion}

RP-HPLC method has been developed for the estimation of PER, IND, and AML simultaneously in bulk and its pharmaceutical dosage form. The \%RSD value was found for the validation parameter that indicates the preciseness of the proposed method and is applicable for routine analysis for the quantitative determination of PER, IND, and AML in bulk and its pharmaceutical dosage form using the proposed RPHPLC method. The statistical analysis of data indicates that the method is reproducible, selective, accurate, and robust.

\section{Abbreviations}

HPLC: High-performance liquid chromatography; RP-HPLC: Reverse-phase high-performance liquid chromatography; HBP: High blood pressure; PER: Perindopril erbumine; IND: Indapamide; AML: Amlodipine besylate; OPA: Orthophosphoric acid; LOQ: Limit of quantitation; LOD: Limit of detection; \%RSD: Relative standard deviation; Rt: Retention time 


\section{Acknowledgements}

All authors are very thankful to the Indukaka Ipcowala College of Pharmacy, New Vallabh Vidyanagar, and SICART, Vallabh Vidyanagar, for providing necessary facilities to carry out the research work.

\section{Authors' contributions}

All authors associated with this research work declared that there is no conflict of interest for publication of work. All authors have read and approved the manuscript. The contribution of each authors are mentioned below: KP: He is a post graduate student and the above work has been carried out by him as dissertation work. UC: He is a mentor of KP and under his noble guidance proposed method has been developed and validated as per ICH guideline. He is also giving training for ease of operation sophisticated reverse-phase liquid chromatography instrument and involved in interpretation of data. HK: She is a co-mentor of KP and under her noble guidance student can understand the concept of mobile phase selection and how to optimize chromatographic conditions. She is also involved in interpretation of data. JP: Through his good relationship with the pharmaceutical industry, we have received all active pharmaceutical ingredients and he is having sound technical knowledge Waters HPLC software system.

\section{Funding}

This research did not receive any specific grant from funding agencies in the public, commercial, or not-for-profit sectors.

\section{Availability of data and materials}

All data and material are available upon request.

\section{Ethics approval and consent to participate}

Not applicable

\section{Consent for publication}

Not applicable

\section{Competing interests}

No competing interests to declare.

Received: 11 May 2020 Accepted: 31 August 2020

Published online: 07 November 2020

\section{References}

1. https://pubchem.ncbi.n/m.nih.gov/compound/Perindopril-erbumine. Accessed 20 July 2019

2. https://pubchem.ncbi.nlm.nih.gov/compound/Indapamide. Accessed 20 July 2019

3. https://pubchem.ncbi.n/m.nih.gov/compound/Amlodipine\%20besilate. Accessed 20 July 2019

4. Ramzia I, Bagary EL (2017) A validated HPLC method for simultaneous determination of Perindopril Arginine, Amlodipine, and Indapamide: application in bulk and in different pharmaceutical dosage forms. J AOAC Int 100:992-999

5. Saravanan G (2014) Development and validation of RP-HPLC method for simultaneous analysis of Perindopril and Indapamide in bulk and combined pharmaceutical dosage form. Asian J Res Chem 7:182-186

6. Dewani MG (2010) Development and validation of stability indicating HPTL C method for determination of Perindoripil Erbumine. Int Res J Pharm 1 428-435

7. Patel DB (2012) Simultaneous estimation of Amlodipine Besylate and Indapamide in a pharmaceutical formulation by a high performance liquid chromatographic (RP-HPLC) method. Sci Pharm 80:581-590

8. Erk N (2001) Comparison of spectrophotometric and HPLC method for the determination Perindopril and Indapamide in pharmaceutical formulations. J Pharm Biomed Anal 26:43-52

9. Jain PS, Badreshiya PR, Chalikwar SS, Todarwal AA (2010) Validation of a dissolution method with RP-HPLC analysis for Perindopril Erbumine and Indapamide combination tablet. J AOAC Int 93:108-115

10. Tiwar R (2012) Multicriteria optimization methodology in development of HPLC method for simultaneous estimation of Indapamide and Perindopril in bulk drug and its combined dosage form. Asian J Pharm Clin Res 2:50-53
11. Gandhi SV (2014) Development and validation of stability indicating RPHPLC method for determination of Indapamide and Amlodipine Besylate. Indian J Pharm Educ Res 48:48-54

12. Raj MV (2012) Development and validation of RP-HPLC method for simultaneous estimation of Amlodipine Besylate and Indapamide in tablet dosage form. Int J Pharm Sci Res 3:3146-3150

13. Shah RN, Gandhi DB, Patel MM (2012) RP-HPLC method for simultaneous estimation of Amlodipine Besylate and Indapamide in tablet dosage form. Asian J Res Chem 5:633-636

14. Desai AK (2012) HPTLC method for the simultaneous estimation of Amlodipine Besylate and Indapamide in tablet formulation. Asian J Res Chem 5:510-514

15. Prajapati J (2011) Analytical method development and validation of Amlodipine Besylate and Perindopril Erbumine in combine dosage form by RP-HPLC. Int J Pharm Res 3:801-808

16. Gumustas M (2013) A validated stability-indicating RP-LC method for the simultaneous determination of Amlodipine and Perindopril in tablet dosage form and their stress degradation behavior under $\mathrm{ICH}$-recommended stress conditions. J AOAC Int 96:751-757

17. Rajua VB, Rao AR (2011) Simultaneous estimation of Perindopril and Amlodipine in combined dosage form by RP-HPLC method. Int J Chem Sci 9:1290-1298

18. Nekkala K (2014) Method development and validation of stability indicating RP-HPLC method for simultaneous estimation of Perindopril Erbumine and Amlodipine Besylate in bulk and its pharmaceutical formulations. Ame $J$ Alzhi Dise Deme 4:672-685

19. Patel BK (2016) Analytical method development and validation for simultaneous estimation of Amlodipine Besylate and Perindopril Arginine in combined pharmaceutical dosage form. Pharm Biol Eval 3:120-128

20. Zaazaa HE, Abbas SS, Essam HM, Mohammed G (2013) Validated chromatographic methods for determination of Perindopril and Amlodipine in pharmaceutical formulation in the presence of their degradation products. Bard Chrom Sci 51:533-543

21. Chitlange SS, Mohammed I, Sakarkar DM (2008) RP-HPLC method for simultaneous estimation of Amlodipine and Metoprolol in tablet formulation. Asian J Pharm 12:232-234

22. Muhammad A, Akhtar T (2014) Simultaneous estimation of Rosuvastatin and Amlodipine in pharmaceutical formulations using stability indicating HPLC method. Br J Pharm Sci 50:629-638

23. Moon HW, Mehmood YA, Hyung KC (2014) Evaluation of stability and simultaneous determination of Fimasartan and amlodipine by a HPLC method in combination tablets. Asian J Pharm Sci 9.123-128

24. Barman RK (2007) Simultaneous high performance liquid chromatographic determination of Atenolol and Amlodipine in pharmaceutical dosage form. Pak J Pharm Sci 20:274-279

25. Shimooka K, Sawada Y, Tatematsu H (1989) Analysis of Amlodipine in serum by a sensitive high-performance liquid chromatographic method with aerometric detection. J Pharm Biomed Anal 7:1267-1272

26. Safeer K, Anbarasi B, Senthilkumar N (2010) Analytical method development and validation of Amlodipine and Hydrochlorothiazide in combined dosage form by RP-HPLC. Int J Chem Tech Res 4:21-25

27. Kansara DA, Chhalotiya UK, Kachhiya HM et al (2020) Simultaneous estimation of amlodipine besylate, Rosuvastatin calcium and Fimasartan potassium trihydrate combination used in the treatment of hypertension using LC method. SN Appl Sci 2:948. https://doi.org/10.1007/s42452-0202758-4

28. Patel K, Chhalotiya U, Kacchiya H, Patel J, Shah D, Nagda D (2020) Simultaneous quantification of Perindopril erbumine, Indapamide and Amlodipine besylate in newer combination of antihypertensive drugs in pharmaceutical dosage form by thin layer chromatography method. Sep Sc plus 3:1-10. https://doi.org/10.1002/sscp.202000010

29. ICH (2005) Validation of analytical procedures: methodology (Q2R1). International Conference on Harmonization, Food and Drug Administration, USA

\section{Publisher's Note}

Springer Nature remains neutral with regard to jurisdictional claims in published maps and institutional affiliations. 